\title{
Implementing Maternal Death Surveillance and Response System: Lessons Learned from the Arab States Region
}

\section{Mohammed Lardi ${ }^{1 *}$, Bouchra Assarag ${ }^{2}$, Halima Mouniri ${ }^{1}$, Radouane Belouali $^{3}$, Mohamed Afifi ${ }^{4}$, Mansour Njah ${ }^{5}$, Hala Bawadi ${ }^{6}$ and Shible Sahbani ${ }^{4}$}

${ }^{1}$ International Freelance, Public Health Specialist, Morocco

${ }^{2}$ National School of Public Health, Ministry of Health, Morocco

${ }^{3}$ International School of Public Health, Mohammed VI University of Health Sciences

(UM6SS), Casablanca, Morocco

${ }^{4}$ United Nations Population Fund, Arab States Regional Office, UNFPA, ASRO

${ }^{5}$ International Freelance Consultant, Tunisia

${ }^{6}$ MCH Nursing Department, The University of Jordan, Jordan

*Corresponding Author: Mohammed Lardi, International Freelance, Public Health Specialist, Morocco.
Received: September 04, 2021

Published: November 26, 2021

(C) All rights are reserved by Mohammed

Lardi., et al.

\section{Abstract}

Context: For many years, MDSR has been implemented in many countries including Arab States Region. The literature review shows that interventions are poorly documented in the Arab States Region. Our objective is to assess the implementation of the MDSR in 5 Arab States Region and point out the challenges faced in order to disseminate good practices and come up with a set of recommendations toward improving the MDSR systems in the all Arab States Region.

Method: The analysis was conducted in five countries: Egypt, Sudan, Jordan, Tunisia, and Morocco. In line with the World Health Organization's guidelines and tools, the research team explored four essential components: (i) Maternal health status in the country (ii) MDSR policy and strategy (iii) MDSR governance, mainly stakeholder participation and legislation, and (iv) MDSR process. Each country team has developed a preliminary report that was first validated by the country team then shared with the regional research team who developed a regional report summarizing MDSR in these countries. National and regional reports were presented in a regional expert group meeting and validated by the technical committee. In this research, the evaluation methodology adopted is based on three dimensions: First, an analysis of maternal mortality context and maternal health in the country as well as analysis of demographic and health system context. Then a quantitative and qualitative analysis of the process MDSR was conducted. Finally, case studies were reported from each country.

Results: The findings showed that MDSR has been widely implemented but with varying degrees of political commitment, allocated resources, governance and processes. an under-reporting of deaths due to a) low commitment of health professionals, decision makers and university hospitals, b) limited coverage of civil registration and vital statistics (CRVS) [1] among the rural population and c) reluctance of the private sector to share data. In addition, maternal deaths notified through MDSR systems are higher than those provided by the routine health management information system. For all countries, notified cases are not all reviewed and financial constraints represent a real threat for ensuring regular meetings of review committees and developing and producing MDSR reports. No country has a clear dissemination strategy to allow a timely use of data and evidence-based decision-making. In some countries,

Citation: Mohammed Lardi., et al. "Implementing Maternal Death Surveillance and Response System: Lessons Learned from the Arab States Region". Acta Scientific Medical Sciences 5.12 (2021): 166-178. 
the recommendations are translated into an action plan. Very often, they do not allow regular monitoring as they are not time-bound and there are no clear indicators set ahead to measure change.

Conclusion: Although MDSR has been widely implemented there is still a need for a concrete high-level operational commitment that sets the foundations for the legislative and legal framework. MDSR is a complex health system strengthening process that needs to be enhanced and linked to an improved civil registration and vital statistics (CRVS) system. Also, there is a gap between surveillance and response components that calls especially for prompt and strong decision based on the evidence generated by the MDSR system.

Keywords: Maternal Mortality; Maternal Death Surveillance System and Response; Civil Registration and Vital Statistics; Arab States Region

\section{Introduction}

All countries are committed to the implementation of UN Global Women and Children Health Strategy. Since the Safe Motherhood Initiative (1987) Much emphasis has been placed on reducing maternal mortality. In 2000, the MDGs broadened the emphasize on maternal health, particularly MDGs 4 and 5 that aim to reduce maternal mortality by $3 / 4$. Countries' commitment has resulted in the development and implementation of five-year national plans. Hence, several national plans [7-10] have been developed aiming at accelerating the reduction of maternal mortality, particularly through eliminating preventable deaths, that account for $75 \%$ of the overall maternal deaths. MDSR related activities are well identified and integrated in different ways: either in the sectoral plan (Morocco), or in a separate plan (Sudan) or in a ministerial circular or a decree for the other countries.

\begin{tabular}{|c|c|c|c|c|c|}
\hline Indicator & Egypt & Jordan & Morocco & Sudan & Tunisia \\
\hline Population X1000 habitants (2018) & 92115 & 10300 & 35220 & 41985 & 11435 \\
\hline \% of urban population & 42 & 90 & 62 & 31 & 68 \\
\hline Maternal Mortality Ratio (2017)* & 37 & 46 & 70 & 295 & 43 \\
\hline \% FP satisfied demand for Modern methods & 81 & 61,9 & 78,5 & 33,3 & 74,7 \\
\hline \% of ANC visits more than 4 (2017) & 87,8 & 83,2 & 60,9 & 50,7 & 85,4 \\
\hline \% Skilled birth attendance & 91,5 & 99,6 & 86,5 & 77 & 97 \\
\hline Total fertility rate & 3,5 & 3,38 & 2,4 & 5,2 & 2,2 \\
\hline Average age at first marriage & 21.6 & 23,4 & 26.8 & 21.5 & 27.7 \\
\hline Number of women in reproductive age (15-49 & 24.4 & 2,42 & 9.25 & 9.5 & 3.06 \\
\hline years) in million & & & & & 2 \\
\hline \% Marriage of girls under (18) & 17 & 8 & $16,7 *$ & 34 & 20 \\
\hline
\end{tabular}

Table 1: Reproductive health status indicators [1].

Percentage of Married girls under 18 years. All sources are from [15] except for Morocco [11] from ENPS, 2018.

Although skilled birth attendance has improved, for many reasons, such as cultural norms, education levels, financial inaccessi- bility, and poor quality of facility-based care, home birth will undeniably continue to occur in Sudan and Morocco.

In 2016, the five countries registered altogether 2742 maternal deaths with a positive correlation between demographic data and Maternal Mortality Ratio in each country. 
Maternal mortality is a relevant indicator to appreciate women's health status, including their access to health care, and the adequacy of the health care system response to their needs. However, there are real limitations to measure, particularly when civil registration of deaths and causes of deaths is weak. The information that countries need to address maternal mortality goes beyond just measuring the level of the problem. Policymakers ask, "Why do maternal deaths occur and what can be done to prevent them?" Program managers ask, "Where things are going wrong and what can be done to address them?" The main complications leading to maternal death are well known: hemorrhage, infection, pre-eclampsia, eclampsia, and unsafe abortion [2].

Maternal death surveillance and response (MDSR) is a continuous cycle: notification, review, analysis, and response. It seeks to avert preventable maternal death through involving all stakeholders in the process of identifying maternal deaths, understanding why they happened, and taking the right action to prevent similar deaths in the future. The concept emerged in the era of the Millennium Development Goals (MDGs) and has become widely established globally [3].

Maternal Death Surveillance and Response (MDSR) allows systematic and timely identification and notification of maternal deaths. It helps quantify death cases and determine its causes. It is also intended to provide adequate answers to the problems diagnosed in the form of maternal mortality recommendations and action plans [2].

MDSR process includes mandatory reporting and integration in the deaths notification system, identification and reporting of maternal deaths, maternal death review, data analysis and aggregation, response, dissemination of the results, recommendations, monitoring and evaluation (M\&E) [3].

Our research team conducted a study in five countries: Egypt, Jordan, Morocco, Sudan, and Tunisia. The purpose of this study is to generate information that could guide country interventions to strengthen the MDSR system across all its components.

Our main objectives are to assess MDSR implementation success and failure as well as the challenges faced. Then, good practices and sound set of recommendations will be disseminated toward improving MDSR systems in the Arab States Region.
There is ambiguity in vision and founding principles in relation to the rationale for the approach. MDSR is a health system strengthening process: "The MDSR is a complex health system strengthening process that takes time to complete the continuous action cycle" [20].

The Institutionalization of MSDR sets the foundations for a sustainable system at different levels along with the commitment of different sectors [20]. MDSR is not adequately institutionalized and the shift from facility based MDR to continuous MDSR that informs the wider health system is still to be achieved [18]. Should the MDSR be integrated in the epidemiological surveillance programs? There is a gap between the notion of surveillance and the notion of response: No harmony between information and action. Need to strengthen the Response component: "The Response component is currently in the shadow of Surveillance component and should be equally implemented and both monitored to ensure progress in achieving quality maternal health care toward reducing maternal deaths - the stated goals of the MDSR.

Literature review shows that interventions in this Arab Region are poorly documented compared to interventions in Africa regions [19,22,23]. More research is needed within the Arabe States Region with great potential of complementarity and resources pooling between Arab states. The focus of this research should be on the quality of care and the implementation of MDSR. It is important to continue monitoring the opportunities and barriers to implementation to assess country progress through more qualitative approaches, such as case studies, to understand how countries respond to MDSR findings.

\section{Methods}

We conducted the qualitative study through a disk review and focused interviews. We explored the four MDSR essential components: [4] (i) maternal health status in the country (ii) MDSR related policy and strategy (iii) MDSR governance, mainly stakeholder participation, and legislation, and (iv) MDSR process including declaration, notification, review, analysis, dissemination, use of the results, response, monitoring and evaluation [5].

A protocol has been developed and validated on the ground by a group of national experts from the 5 countries and resource persons from Ministries of Health, universties, UNFPA ASRO. The study 
protocol is structured according to the different components of the MDSR: Country profiles, Policy and strategy, governance, MDSR process (Identification, notification, review and analysis, dissemination, response, resources and monitoring and evaluation) [5].

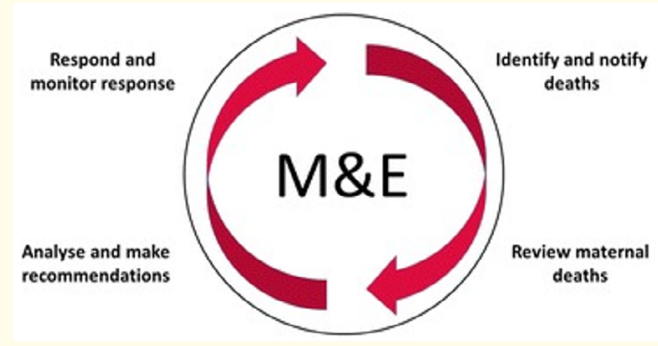

Figure 1: Conceptual model for Monitoring and Evaluation (M\&E).

The continuous cycle of MDSR has four essential components: a) identification and notification of maternal deaths, b) maternal death reviews (MDR), c) analysis and recommendations and d) response and monitoring (Figure 1). Through its cycle, MDSR mirrors the steps of a typical audit or quality improvement cycle.

For each component, a series of quantitative and qualitative questions were developed. Then each country team informed the questionnaires based on the documentation available and the results of interviews with the country's resource persons.

Based on WHO MDSR related guidelines and tools [5], our research team developed 12 data collection grids specific to each MDSR component including quantitative and qualitative questions. A technical committee composed of resource persons involved in MDSR (Ministry of Health, United Nations Population Fund (UNFPA), Universities and field health professionals). The grids were then shared with each country research team leader for review and validation with all stakeholders.

The grids were completed using available data in each country such as annual statistical reports, DHS, MDSR reports. In addition, interviews were conducted with key senior management cadres at the Ministry of health (national and subnational level), and relevant stakeholders (UN agencies, USAID, and INGOs) in the country.

Field visits were carried out in all countries by the national research focal point [6]. The objective was to conduct interviews and have a practical insight in the process and assess the quality of available documents.. In Egypt, the research focal point attended the safe motherhood committee meetings held at the hospital. In addition to the evaluation form, field visits allowed review of sample data and forms related to the last 6 months of 2017. This includes the monthly report forms coming from the governorates "DNF, MMSSQ, SMC reports and the summary report of cases.

Interviews were conducted with health professionals, at regional, national and international level and who contributed in the development and the implementation of the MDSR system in the country: This includes representatives from the United Nations agencies (UNFPA, WHO, and UNICEF), donors and government Aid groups, Ministry of Health, professional bodies, NGOs, academics and researchers, independent consultants. Members of National and regional committee responsible for deaths reviews, the MDSR focal points, persons responsible for data collection and notification of death cases, maternal health programs managers and health professionals at primary and secondary levels, School of medicine Teachers; professional societies, particularly Obs/Gynecology and neonatology.

Each research country team member developed a preliminary report [6] that was first validated at the country level then shared with MDSR research team at the University of Health Sciences Mohammed VI in Casablanca. For advocacy purpose, each country developed a policy brief. Based on the five-country reports, the research team produced a summary report with the main findings and shared with the countries for review. The dissemination of all the reports/study results took place in a regional workshop. In addition, to expand dissemination of, and the countries access to the findings, all the material has been posted in online [6].

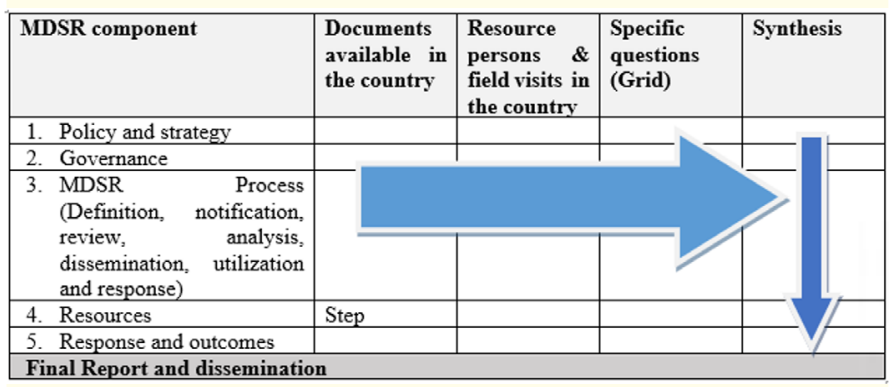

Figure 2: Data collection model and stages. 


\section{Results}

Our study showed that the five countries have globally implemented MDSR but with varying degrees of political priority, allocated resources, governance, and processes: While Egypt started very early, other countries like Jordan are still looking for extension.

Also, there is delay in the extention process due to donor fatigue. MDSR is still in the pilot status, vertical, and poorly integrated into maternal health programs and health system particularly, in the epidemiological surveillance programs. implicit finality for implementing MDSR is common and would be the achievement of MDG 4 and 5.

\section{Are MDG'S goals meet?}

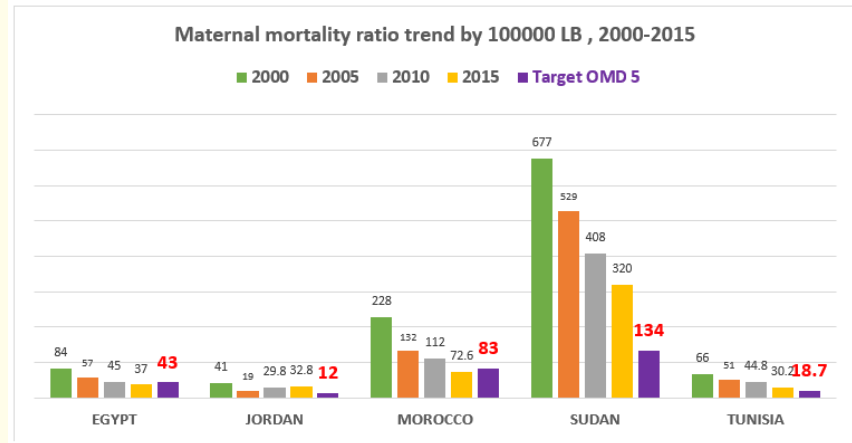

Graph 1: Trend of maternal mortality in 5 countries (2000-2015) Sources:

- Trends in maternal mortality: 1990 to 2015: estimates by WHO, UNICEF, UNFPA, World Bank Group and the United Nations Population Division.

- Tunisia, National health survey

- Morocco, National population and family survey

- $\quad$ Egypt, Demographic health survey

- Jordan, Population family health survey

- Sudan, Household health survey

\section{4 countries out of 5 have not reached the MDG'S goal}

In our results analysis, we tried to answer the following main questions:

- $\quad$ Policy and strategy: What is the degree of policy ownership given to MDSR?

- Governance: What is the model and effectiveness of governance?
- Process: What are the process and results of the process model (identification, notification, review, analysis, dissemination)?

- What is the model and results for monitoring and evaluation?

- In general, is the implementation of MDSR in the country well advanced?

- What have been the most important contributions of MDSR?

\section{Policy and strategy}

MDSR related activities are clearly identified and integrated in different ways for each country: in the sectoral plan for Morocco, in a separate plan for Sudan, in a ministerial circular or decrees for the other countries. For the five countries, MDSR does not cover the complete geographical territory.

Despite the priority given to MDSR at the political level, lack of funding represents a real threat to its sustainability. While there is political support and commitment at the national and local level, long-term funding of MDSR raises questions about its sustainability in the end.

Governance and Leadership: What is the model and effectiveness of governance?

There is a commitment at high political level, however, there is a lack of maintaining leadership and engagement of all operational decision-makers at central, regional, and local levels. For all countries, a central unit ensures coordination through the usual administrative means of communication and through participation in meetings. There is a challenge in coordinating several external and internal actors mainly, the ministry of health and the Ministry of the Interior (Morocco) and within the health department at different levels. Also, there is a lack of harmony between information and action. Information arrives late which delays the production of reports., Malaysia with 22 years of rollback of MDSR implementation published 6 reports. In Morocco, three reports in eight years. South Africa experience is interesting as this country produces an annual statistical report and an analytical report every three years.

For all countries, MDSR is under the Ministry of Health leadership. National Committees and sometimes Regional Committees are in charge of MDSR implementation and follow up. Potential partners (Universities, NGOs, private and other sectors) are poorly contributing.

Regarding MDSR related Laws and Regulations, the 5 countries rely on the legislation especially, ministerial decrees and circulars: 
- $\quad$ Egypt: Ministerial Decree No. (159)/1999 was issued to notify all maternal deaths in the maternal and child health facilities and in the National Health Information Center (NHIC)

- Jordan: Monitoring the maternal mortality system during pregnancy, childbirth and puerperal diseases published under Article 27 of the Public Health Law

- $\quad$ Morocco: Ministerial circular (No. 24 of 6 January 2009).

- Tunisia: Decree No. 26/99 of 1999 (Establishment of a system for monitoring and investigation of maternal deaths in hospitals)

- Sudan: The 2009 ministerial decree stipulates that all maternal deaths must be notified.

Indeed, we will find that in most countries, departmental circulars govern the MDSR.

At political level, despite the high policy commitment, MDSR is considered as a project funded by international organizations. Such inconsistency between the political decision and the level of national funding remains a real threat to MDSR sustainability. It's the case of Jordan, Morocco and Tunisia where MDSR does not cover all the geographical territory of the country.

MDSR processes: What are the process and the results of the process model (identification, notification, review, analysis, dissemination)

\section{Identification and notification}

Any maternal death, regardless of age and nationality is a mandatory reporting event by law and circulars in all five countries; the notification has been strengthened by this obligation. The number of reported deaths varying from one country to another and from one year to another. In 2016, Tunisia, registered 53 deaths, Jordan 110, Sudan 1198, and Egypt 1194 (given the number of births estimated at 2.6 million in 2016 in Egypt compared to 72168 in Jordan). For Morocco, 187 deaths were notified in 2015 through MDSR system at the national level $(78 \%$ of the expected maternal death).

Although verbal autopsy (VA) approach is a mandatory in these countries, it was difficult to apply. I In Egypt (50\%), Morocco (29/35), Sudan (187/1198), Tunisia (none). The limited use of VA could be related to health professionals reluctance, lack of trans- portation means, and irrelevance when $95 \%$ of births are institutional births. Under-reporting of deaths is common. According to WHO, the performance of vital registration and vital statistics systems in the region is low and very heterogeneous: (i) Delays between death and reporting, and between declaration and regional review committee meeting (ii) Low commitment of some university hospitals, and reluctance of the private sector to provide death records (Sudan and Morocco) (iii) Lack of commitment and motivation of health professionals. The involvement of medical syndicates and professional bodies related to $\mathrm{Ob} / \mathrm{Gyn}$ in the regional and national review committees could encourage the private sector to be a part of MDSR. This action needs to be reinforced by legislation.

The delay between the date of death and the declaration to the competent services differs from one country to another. For Morocco, 24 hours in case of institutional maternal death. For Tunisia, it is around 8 days and does not meet deadlines in case of homebased death.

In five countries, migrants' deaths are reported. This category of 2,918,125 displaced people represents a serious burden, especially in Jordan. In Tunisia, beyond regulatory problems, a number of factors constitute obstacles to the effectiveness of migrants' access to health care and services especially restriction on abortion services. Tunisia has concluded social security agreements to provide for the application of the host country's social security legislation with Maghreb Arab countries. In Morocco, migrants have full access to all health services and national programs. Likewise, in Sudan and Egypt migrants benefit from health services as part of the overall health system.

\section{Maternal death review}

The notified deaths are not all reviewed mainly due to case summary incompleteness. In Morocco, $17 \%$ of home deaths and $10 \%$ of institutional cases have incomplete information. For two countries, medical records (patient file, obstetric, ICU registers) need to be harmonized with MDSR tools especially notification and case summary forms in order to decrease the proportion of incomplete forms. In the meantime, MNH care providers should be trained on these tools. For all countries, financial shortage remains a real threat for ensuring review committees' meetings as well as development and production of MDSR reports. 


\section{Maternal death analysis}

Four out of the five countries report that the analysis relays on data recorded in the cases files. The table 2 provides four important evidences that can guide response actions:

- The notified cases are not all reviewed,

- $\quad$ Direct cause death rates are similar to those reported in the literature: six to eight out of ten women die from direct causes, particularly hemorrhage, eclampsia/pre-eclampsia and sepsis;

- $\quad$ Availability factors are related to the place of death. Thus, in case of institutional maternal death, health service-related

\begin{tabular}{|l|c|c|c|c|c|}
\hline & Egypt & $\begin{array}{c}\text { Jordan* } \\
{[16]}\end{array}$ & $\begin{array}{c}\text { Morocco } \\
{[17]}\end{array}$ & $\begin{array}{c}\text { Sudan } \\
{[18]}\end{array}$ & $\begin{array}{c}\text { Tunisia } \\
{[10]}\end{array}$ \\
\hline $\begin{array}{l}\text { Number of MD } \\
\text { notified }\end{array}$ & 1194 & 62 & $187^{*}$ & 1198 & 94 \\
\hline $\begin{array}{l}\text { \% MD re- } \\
\text { viewed }\end{array}$ & 50 & 100 & $87^{*}$ & 71 & 75 \\
\hline $\begin{array}{l}\text { \% Institutional } \\
\text { MD }\end{array}$ & 76 & NA & 75 & 84,4 & 87,5 \\
\hline $\begin{array}{l}\text { \% Home based } \\
\text { MD }\end{array}$ & 24 & NA & 25 & 15,6 & 12,5 \\
\hline $\begin{array}{l}\text { \% Direct } \\
\text { Causes }\end{array}$ & 65,9 & 56,5 & 78 & 71 & 67,2 \\
\hline $\begin{array}{l}\text { \% Indirect } \\
\text { Causes }\end{array}$ & 34,1 & 33,9 & 13 & 22,5 & 32,8 \\
\hline $\begin{array}{l}\text { \% Unknown } \\
\text { Causes }\end{array}$ & NA & 9,7 & 9 & 6,2 & NA \\
\hline \% avoid ability & 77,9 & 73,2 & 89 & 72,6 & 75,4 \\
\hline
\end{tabular}

Table 2: Analysis of maternal death (MD) by death area and causes.

factors prevail, whereas for home-based maternal death, family and community-related factors are predominant factors.

- $\quad$ High rates of availability for all five countries, at least seven out of ten women deaths could have been averted.

All statistics are from national MDSR 2016 reports. Statistics in the case of Moroccoare from 2015 evaluation report in a represen- tative sample of 6 regions out of 12 .

For Jordan, implementation of MDSR system started in January 2018, with the reporting of deaths among women of reproductive age nationwide. The National Maternal Mortality Report 2018 is the first report for Jordan that provides comprehensive information about each maternal death that took place during the reporting period based on active surveillance. Almost $98 \%$ of births take place in hospitals: hospitals and forensic medicine departments (FMDs) are the only entities entitled to issue a death notification form.

All five countries use IT software (Access, SPSS...) to manage MDSR related data. This tool allows the aggregation, processing, and storage of data at national regional and district level. It is highly advisable to encourage the involvement of the HMIS department in each country and build synergic bridges with the maternal health department to boost coordination between both departments.

\section{Dissemination of the MDSR report}

In four out of the five countries, the national and the regional committees draw up an annual report. The analysis led to the causes of death and avoidance and deaths related factors were well defined. Dissemination of the results faces multiple challenges: There is no clear and focused dissemination strategy to allow timely use of data.

Countries' effort to share information is variable but present in all countries and variety of channels were used. Some opted for a light epidemiological bulletin or simple aggregated pages on maternal mortality situation and other prefer a consistent analytical report. MDSR Reports remains within the health system as a hard copy document distributed upon request, presented in meetings at national and regional levels but no feedback to health professionals or community representatives. Dissemination weaknesses could be explained by the following:

- Low motivation to invest in analysis and production of MDSR reports. Fear of lawsuits if manipulated by the media, because confidentiality within the health system is difficult to ensure because auditors are in the meantime judge and party, 
- Fear of Syndicate and the media,

- $\quad$ Or simply organizational: delay in producing information because data is considered a property of a given institution and preference is devoted first to publishing scientific articles intended for a restricted audience of researchers,

\section{Response in MDSR system}

For some countries despite the recommendations to be translated into national action plans, very often they do not allow regular monitoring as they are not time-bound and there are no M\&E indicators set ahead to measure change. Activities are well defined in terms of areas of improvement, but the formulation remains global and non-specific in time and space.

Is the implementation of MDSR well advanced in the country?

In all five countries, any maternal death is a notifiable event. The regional committee gathers all women of reproductive age deaths then ensures deaths related to pregnancy and births. A national death review committee meets regularly, and the two committees meet at a pace that varies from country to country. Maternal deaths have been reported and the proportion of cases investigated is quite high and varies from country to country. We note however, that the completeness of the files varies from one country to the other. In Morocco, $17 \%$ of home deaths and $10 \%$ of institutional cases have incomplete information. In all five countries, the analysis led to the causes of death, and the factors were well defined. As for the response, activities are well defined in terms of areas of improvement but the formulation remains global and non-specific in time and space. No country has come to a response with an action plan with timelines and responsibilities.

The main objective of the MDSR is to put in place actions toward eliminating preventable maternal deaths. In our study M\&E is not put in place correctly, that explains why the system has achieved partially its goal.

\section{Discussion}

Policy and strategy

MDSR related activities are clearly identified and integrated in different ways depending on the country: in the sectoral plan (Morocco), or in a separate plan (Sudan) or in a ministerial circular or in decrees for other countries. For the five countries, MDSR does not necessarily cover the complete geographical territory of all five countries.

Despite the priority given to MDSR at the political level, lack of funding poses a real threat to its sustainability. While there is political support and commitment at the national and local level, the fact that indeed, MDSR is seen as a project funded by international organizations raises questions about its long-term funding sustainability in the end.

In all five countries, all stakeholders have endorsed the relevance of the MDSR strategy. Tunisia and Jordan have focused on deaths in hospitals; while Morocco, Sudan and Egypt have included the verbal autopsy for home-based deaths due to high share of home births in Sudan (>70\%) and the importance of mortality in rural areas compounded by a low death registration coverage (in Sudan and Morocco).

Reliable data on the levels and causes of mortality are cornerstones for building a solid evidence for health policy, planning, monitoring and evaluation. Verbal autopsy (VA) is a method used to ascertain the cause of death based on interviews with next of kin or other caregivers.

In settings where the majority of deaths occur at home and where civil registration systems do not function, there is little chance that deaths occurring away from health facilities will be recorded and certified as causes of death. For such case, WHO [2,4,5] recommend VA as a primary source of information about causes of death. VA has become an essential public health tool for direct estimation of the cause of mortality at community or population level, although it may not be an accurate method for attributing causes of death at the individual level.

\section{Governance}

Is MDSR considered a priority in the country's policy?

In general and for the five countries, the priority level of MDSR system remains "Medium". It is interesting to do an analysis exercise for each country based on objective criteria, some of which are: Institutionalization of MDSR in the official sectoral strategy documents; the level of financial resources committed to MDSR; the degree of commitment of local authorities and health professionals through certain indicators, such as: the percentage of maternal deaths reported compared to expected deaths, the percent- 
age of the files investigated and the degree of completeness of the records; the delay in the preparation of national reports and the extent of dissemination of recommendations; the degree of the implementation of the recommendations mentioned in the reports and the degree of achievement of the objectives reconciled with the mission of the committees set up.

\section{Have sufficient resources been allocated to MDSR?}

In all five countries, resources allocated are insufficient. In addition to UNFPA and WHO, many influential actors are committed and can support the implementation of MDSR including civil society and/other state departments. The institutionalization of the confidential audit of maternal and neonatal deaths in the sector strategy document is a relevant platform to advocate for increasing the state budget.

\section{What have been the most important contributions of MDSR?}

Increased understanding of death causes and preventable factors. In order of significance, these preventable factors are: a) poor antenatal care, b) inadequate treatment and c) delayed care by families. In the five countries, MDSR has generated great momentum toward reducing maternal mortality. In these countries, relevant information on the causes and circumstances of death was unveiled and corrective actions were introduced in their national sectoral plans.

State of knowledge in MDSR and global successful experiences

Despite its implementation in many countries, MDSR remains insufficiently institutionalized. The challenge, as it's the case for many health system interventions, is to find a way to provide catalytic assistance and capacity building for MDSR to be integrated into the Healthcare system [5]. Beyond being a simple surveillance intervention of a health phenomenon, MDSR is a complex process of health systems strengthening that takes time to complete a continuous cycle of action. The Response component should be implemented in a harmonious and synergistic manner as to ensure progress in achieving quality maternal care and in reducing deaths.

This requires strong leadership both at national and subnational levels of health systems governance; an appropriate legal framework that protects professional liability while ensuring the commitment of those involved in health care (e.g. public and private, obstetricians, anesthetists, midwives and other specialists to address indirect causes of maternal death) [5].

Multitudes of actors are involved in the MDSR system. United Nations Agencies (WHO, UNFPA, and UNICEF) play a key role in supporting MDSR, however, the capacity of countries to manage MDSR remains a key factor for the success and sustainability of this intervention. In countries where confidential inquiry of maternal deaths is well established, national committees have often been established as a result of increased government commitment to policies and laws aimed at improving maternal health. For example, in the Republic of South Africa (RSA), the Policy of Free Care for Women and Children in 1994 and the 1997 Notification of Maternal Deaths Act were precursors to the National Committee for the Confidential Investigation of Deaths. In 1998, a long history of political commitment to strengthening maternal and child health services has led to several specific initiatives, including the extension of the existing system of maternal mortality audit to a formal process at the national level [4]. In the Republic of South Africa and Malaysia, a strong commitment from national governments has been evident from the early stages, with financial support to review activities at the national level [7,20,24,25]. In Malaysia, South Africa, and the United Kingdom, the Government provides administrative support through secretariats and national committees. In Malaysia, state health directors are even present at death review meetings. In the United Kingdom, although mandated, supported and funded by the Ministry of Health, $t$ confidential investigations is conducted by a consortium of academic institutions. Thus, strong political and technical commitment to improve equity-sensitive information systems is needed in order to monitor the maternal mortality gap, and sound research is necessary to elucidate the major interactions between this public health problem and associated factors. As more countries are moving towards MDSR systems, it is important to continue to monitor opportunities and barriers to full implementation through quantitative means such as the MDSR Global Implementation Survey to evaluate country progress and analyze how countries respond to MDSR conclusions [13]. Countries with the highest number of maternal deaths generally face greater challenges in setting up a system that takes into account all maternal deaths. While notification of all maternal deaths is ideal and essential for accountability to measure progress towards reduction, rescue measures have already been taken by countries in response to the results of maternal deaths without full implementation. Systems should be in place to ensure that all maternal deaths are re- 
viewed or, at the very least, to analyze a sufficient number of cases to avoid prejudices and promote learning system-wide.

Strengths and limitations of the study

The study is in line with WHO guidance to deepen the knowledge and analysis related to the MDSR implementation [4]. Conducted at the level of five Arab states, Egypt, Jordan, Morocco, Sudan, and Tunisia, this study associated both the comparison of the quantitative dimensions of the MDSR but could be more in depth in the qualitative analysis of dimensions related to the MDSR. Thus, a mixed analysis tool has been developed and can serve as a basis for further studies. The dynamics of exchange established between the different researchers who participated in this study is also an important asset in a region where exchanges in this field remain relatively limited.

The main added value of this research is: a) to have investigated for the first time and in depth the policy and the process of MDSR in selected Arab States, b) to have developed assessment tools for each component of the MDSR, a questionnaire with quantitative and qualitative questions that can be easily adapted and adopted by other countries in the Arab States Region and/or beyond.

\section{Policy implications}

For the five countries MDSR produced convincing results at the first implementation stage, then breathlessness took place instead. Therefore, and for the 5 countries, MDSR system calls for revitalization measures toward eliminating preventable maternal deaths.

Invest more in human resources in the field through: a) ensuring equitable regional distribution and retention b) ongoing, training, coaching, monitoring and, motivation. Supportive supervision and capacity building of state MDSR committees are patchy; and there is limited funding for the MDSR system. The maintenance of knowledge of health professionals and listening to the field can provide information on the best possible alternatives. motivate human resources for better quality of data collection in terms of speed and completeness.

Invest in high-level policy and leadership of $\mathrm{MOH}$ :

- The commitment of the five countries toward achieving the SDGs is a golden opportunity for integrating the MDSR in the sectoral strategy as a leverage to improve the quality of care and the human rights. The human factor is the key to success as motivation of health professionals is likely to engage them in the process of MDSR

- Invest more in the involvement of decision-makers in order to revitalize the various ministerial circulars, reinforce advocacy and allow sustainable funding for MDR system.

Organization and coordination should be context bound: MDSR system is seen as a vertical program with little or no linkage and coordination with other relevant departments and programs, university hospitals. The focus on maternal death registry has overshadowed the concept of an institutional collaboration. Here some alternatives:

- Ensuring adequate coordination between all actors outside the health department, between the teams at central and regional level is an absolute and priority necessity. For example, inviting central management to integrate this mechanism into their projects with their partners. Produce and disseminate national guidelines for conducting MDR committee meetings.

- Strengthening the leadership capacity of the central unit and the focal point in the region

- Integrating MDSR into the routine epidemiological surveillance system to make maternal deaths, a reportable event just like epidemic diseases.

- Maternal health services for refugees should be under one umbrella for better services and resource optimization.

Special attention should be given to monitoring at regional level. Monitoring of recommendations so that the MDSR is actionoriented and improves the quality of care locally, which should be the aim of this strategy. About two thirds of maternal deaths (66.4\%) occur within the first 24 hours of their arrival at the hospital. There is a need to lighten the collection and monitoring tools to help health professionals contribute to the success of this approach and ensure that recommended action and interventions have been implemented.

- Information from MDSR system must be produced within the deadlines and disseminated on a large scale. Data must 
be aggregated or depersonalized so that women or caregivers are not identified. Recommendations should be sent back to the hospital or community where the information was collected in a language and method of dissemination suitable for the target audience. Finally, legal guarantees must exist to prevent the results of the review from being used for trial purposes. The key messages should be aimed at those who can implement the recommendations to actually save maternal lives. In addition, policy makers should mobilize sufficient budget from the state for this approach and for implementing the action plan in order to dynamize MDSR, which ensures a gradual exit strategy for the donor agencies.

- $\quad$ More investment should be done to improve notification and review at Community level especially, a) increase awareness about risk factors for pregnant women to improve early referral and reduce the first delay, b) strengthen their national plans for the improvement of civil registration and vital statistics [25] (CRVS) systems aligned to WHO strategy.

\section{Conclusion}

Our objective was to assess the implementation of MDSR in 5 Arab States Region and the challenges faced in order to disseminate good practices. Regarding the implementation of all components of the MDSR, there is a similarity in approach between five countries especially for institutional deaths but also there is a gap between the five countries and between regions within the same country. The analysis of the five country reports showed that: the system is not reflective of maternal deaths reality because of the underreporting of cases and the non-involvement of the private sector. Registration of maternal deaths at health offices are not completed. The reactivity of the system is weak. Despite these weaknesses, there are still some strengths: The introduction of the IT tool in the five countries made MDSR data analysis easier and allows for the analysis of several variants/indicators in search of causes and/or underlying factors related to maternal deaths; Availability of national reports in the five countries help guide the response and enable inter-country benchmarking.

Some challenges remains

- $\quad$ Absence of clear indicators to measure change in terms of quality of MNH care services.

- The limitation of the tool at national and regional levels leads to inaccessibility of hospital teams and local committees to MDSR data while they are key players for problems prioritization and responses.

Such exclusion is likely to affect the commitment of these frontline actors;

- It is necessary to consolidate the accumulated experience over several years by an objective review in order to take benefice out of the good practices and update all MDSR tools.

\section{Competing Interests}

The authors do not declare any financial or non-financial competing interest in relation to this manuscript.

\section{Acknowledgements}

This study was initiated and fully funded by the United Nations Population Fund (UNFPA-ASRO) and its design, implementation and analysis were jointly achieved in partnership with the International School of Public Health at the International School of Public Health, Mohammed VI University of Health Sciences (UM6SS), Casablanca, Morocco.

The case studies were summarized from a series of countries reports with the contribution of the following national experts: Amal Bouziyane (Morocco), Khaled Ahemed Nasr (Egypt), Hala Bawadi (Jordan), Mohammed Anouar Saddate (Morocco), Nada Darkaoui (Morocco), Nada Gaafer Osman Ahmed (Sudan), Mansour Njah (Tunisia) et Safwane Mowafaq (Morocco).

\section{Bibliography}

1. WHO, Regional Office for the Eastern Mediterranean. "Monitoring health and health system performance in the Eastern Mediterranean Region: core indicators and indicators on the health-related Sustainable Development Goals (2019)?" World Health Organization? Regional Office for the Eastern Mediterranean (2019).

2. MOH SUDAN. "National RMNCAH Strategy 2016-2020 in Sudan" (2016). 
3. MOH Morocco. "Plan National 2008-2012 pour l’Accélération de la Réduction de la Mortalité Maternelle et Infantile". Etat d'avancement (2012).

4. MOH Sudan. "Maternal death surveillance and response in Sudan" (2014).

5. MOH Tunisia. "Etat des Lieux de la SMNN en Tunisie". DSSB (2015).

6. WHO. "Regional strategy for the improvement of civil registration and vital statistics system 2014-2019?" (2014).

7. UNFPA. "State of the world, Unfinished business" (2019).

8. MOH Morocco. "Enquête Nationale sur la Population et la Santé Familiale ENPSF" (2018).

9. WHO. "Beyond the numbers: reviewing maternal deaths and complications to make, pregnancy safer?" (2004).

10. WHO. "Time to respond: a report on the global implementation of maternal death surveillance and response?" (2016).

11. RJ Ravichandran J. "Lessons from the confidential enquiry into maternal deaths, Malaysia". British Journal of Obstetrics and Gynaecology 4 (2014): 47-52.

12. Achem FFCO and Agboghoroma. "Setting up facility-based death reviews in Nigeria". British Journal of Obstetrics and Gynaecology 21.S4 (2014): 75-80.

13. HSD Bernis., et al. "Towards elimination of maternal deaths: maternal deaths surveillance and response". Reproductive health 10.1 (2013): 1.

14. M Koblinsky. "Maternal Death Surveillance and Response: A Tall Order for Effectiveness in Resource-Poor Settings" (2017).

15. WHO. "Maternal death surveillance and response: technical guidance information for action to prevent maternal death" (2013).

16. International school of public health; University Mohammed VI; Casablanca; Morocco, "Availability of data and materials the case studies upon which this study is based are publicly available at International school of public health, University Mohammed VI, Moro". International School of Public Health; Mohammed VI University of Health Sciences (UM6SS); Casa- blanca; Morocco (2017).

17. MOH Sudan. "MICS survey report". Sudan (2104).

18. MOH Egypt. "Egypt Demographic and Health Survey (EDHS)" (2014).

19. J MOH. "Department of Statistics (DOS). Jordan statistical Yearbook. The Hashemite of Jordan" 67 (2016).

20. MOH and Morocco. "Rapports sur la surveillance des décès maternels et réponse, (MS, 2010, 2013, 2015)” (2013).

21. MOH Sudan. "NMDSR reports 2010, 2011, 2012, 2013, 2014, 2015, 2016, sudan" (2016).

22. Bandali., et al. "Maternal Death Surveillance and Response Systems in driving accountability and influencing change". International Journal of Gynecology and Obstetrics 135.5 (2016): 367-371.

23. A Saloua., et al. "Preventable maternal mortality in Morocco: the role of hospitals". Tropical Medicine and International Health 18.4 (2013): 444-450.

24. Kurinczuk D., et al. "Mothers and babies: reducing risk through audit and confidential enquiries across the UK ". British Journal of Obstetrics and Gynaecology (2014).

25. WHO. "Improvement of civil registration and vital statistics". Regional Office for the Eastern Mediterranean CRVS (2019).

26. MT UNFPA. “États des milieux de la santé maternelle et néonatale en Tunisie". 2ème edition (2017).

27. T MOH. "Objectifs du millénaire pour le développement: réalisation et disparités régionales en Tunisie". NEW MEDIT (2011).

28. République Tunisienne. "Rapport national sur la population et le développement, le caire +20 ” (2013).

29. JD MOH. "1990-2012 Jordan Population and Family Health Surveys". Trends in Demographic and Health Indicators in Jordan (2012).

30. UNFPA. "State of the world". unfinished business (2019).

31. E Mansour and K Nasr. "Report Review of Egyptian MMSS at MCH-MOHP" (2016). 
32. HCP Morocco “Recensement Morocco”. (2014).

33. MOH and Tunisia. Meeting under the theme: "Maternal Mortality. For how long?" Tunis declaration On Maternal Newborn and Child Health, 20. no. Campaign for the Accelerated Reduction of Maternal Mortality in Africa (CARMMA, (2011).

34. PNUD. Tunisia "Rapport sur le développement humain" (2016).

35. Office National de la Famille et de la Population; Tunisia, Enquête Nationale sur la Mortalité Maternelle en Tunisie 20092010 (2010).

36. Moodley., et al. "The confidential enquiry into maternal deaths in South Africa: a case study". British Journal of Obstetrics and Gynaecology 4 (2014): 53-60.

\section{Volume 5 Issue 12 December 2021}

(C) All rights are reserved by Mohammed Lardi., et al. 